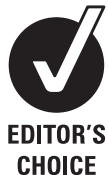

CHOICE

\title{
Sexual and HIV risk behaviour in Central and Eastern European migrants in London
}

\author{
Fiona M Burns, ${ }^{1}$ Alison R Evans, ${ }^{1}$ Catherine H Mercer, ${ }^{1}$ Violetta Parutis, ${ }^{2}$ \\ Christopher J Gerry, ${ }^{2}$ Richard C M Mole, ${ }^{2}$ Rebecca S French, ${ }^{3}$ John Imrie, \\ Graham J Hart ${ }^{1}$
}

\begin{abstract}
- Additional materials are published online only. To view these files please visit the journal online (http://sti.bmj. com).

${ }^{1}$ Centre for Sexual Health and HIV Research, Research Department of Infection and Population Health, University College London, London, UK ${ }^{2}$ The School of Slavonic and East European Studies, University College London, London, UK

${ }^{3}$ Department of Social and Environmental Health Research, London School of Hygiene and Tropical Medicine, London, UK ${ }^{4}$ The Africa Centre for Health and Population Studies, University of KwaZulu-Natal, Mtubatuba, South Africa
\end{abstract}

\section{Correspondence to} Dr Fiona M Burns, UCL Centre for Sexual Health and HIV Research, Mortimer Market Centre, Off Capper Street, London WC1E 6JB, UK; f.burns@ucl.ac.uk

Accepted 3 April 2011

\begin{abstract}
Background Accession of 10 Central and Eastern European (CEE) countries to the EU resulted in the largest migratory influx in peacetime British history. No information exists on the sexual behaviour of CEE migrants within the UK. The aim of this study was to assess the sexual lifestyles and health service needs of these communities.

Methods A survey, delivered electronically and available in 12 languages, of migrants from the 10 CEE accession countries recruited from community venues in London following extensive social mapping and via the Internet. Reported behaviours were compared with those from national probability survey data.

Results 2648 CEE migrants completed the survey. Male CEE migrants reported higher rates of partner acquisition (adjusted OR (aOR) 2.1, 95\% Cl: 1.3 to 2.1 ) and paying for sex (aOR 3.2, 95\% Cl: 2.5 to 4.0), and both male and female CEE migrants reported more injecting drug use (men: aOR 2.2, 95\% Cl: 1.3 to 3.9; women: aOR 3.0, $95 \% \mathrm{Cl} 1.1$ to 8.1 ), than the general population; however, CEE migrants were more likely to report more consistent condom use and lower reported diagnoses of sexually transmitted infections (STI). Just over $1 \%$ of respondents reported being HIV positive. Most men and a third of women were not registered for primary care in the UK.
\end{abstract}

Discussion CEE migrants to London report high rates of behaviours associated with increased risk of HIV/STI acquisition and transmission. These results should inform service planning, identify where STI and HIV interventions should be targeted, and provide baseline data to help evaluate the effectiveness of such interventions.

\section{INTRODUCTION}

Over the past decade, the UK has experienced large migratory fluxes from Central and Eastern Europe (CEE). In particular the accession on 1 May 2004 of Czech Republic, Estonia, Hungary, Latvia, Lithuania, Poland, Slovakia and Slovenia (the 'A8') into the European Union (EU), and of Bulgaria and Romania (the 'A2') on 1 January 2007, was followed by large-scale, though often, circular migration from these countries. ${ }^{1}$ Circular migration is a form of migration that allows some degree of legal mobility back and forth between two countries.

The uptake of safer sex measures and patterns of health service use in these migrant populations is unknown. Also the demographic profile of CEE migrants (young and frequently single), ${ }^{1}$ the often high background prevalence of sexually transmitted infections (STIs) and HIV in their countries of origin, $^{2-4}$ and their lack of experience of the British health system may place these new migrant communities at higher risk of sexual ill health and reproductive morbidity compared with the general population.

As research on the sexual behaviour of the general populations of CEEs is sparse and no information exists on the sexual behaviour of CEE migrants within the UK, our aim was to establish an understanding of the sexual lifestyles and health service needs of these communities. This study is part of the SALLEE (sexual attitudes and lifestyles of London's Eastern Europeans) project. Papers examining the sexual risk of CEE migrant men who have sex with men ${ }^{5}$ and CEE migrant attendance at genitourinary medicine clinics and STI diagnoses, ${ }^{6}$ which arise from this project as well, are also published in this issue of STI.

\section{METHODS}

A detailed description of the methodology has been previously published. ${ }^{7}$ A brief summary is provided below.

\section{Participants and procedure}

Eligible respondents were literate men and women aged over 17 who self-identified as migrants from one of the $10 \mathrm{CEE}$ countries. The community sample was recruited in London and the web survey was advertised on websites for CEE nationals in the UK as described in reference 7. Web survey respondents who gave their home post-code outside London were excluded from the study.

Fieldwork took place over a 9-month period (July 2008-March 2009). The nine fieldworkers involved in the recruitment of respondents for the community sample were native speakers of six of the languages of the CEE countries.

\section{Study instruments}

The survey instrument was a self-completed questionnaire designed using SNAP 9 survey software (Snap Survey Ltd., Bristol, UK) that was fielded using hand-held computers for the community sample and a web survey for the Internet sample. The community and internet survey questions were identical. The questionnaire was anonymous. The questionnaire was piloted to examine: its feasibility and acceptability and to explore the understanding of the question items and underlying constructs; the use of the hand-held computers, question routing and technical usability were also tested during piloting. 
The questionnaire was translated into 11 languages (the 10 official languages of the CEE countries plus Russian) and bilingual native speakers of the 11 languages checked the translation accuracy.

\section{Sampling}

There is no adequate sampling frame of this new migrant population from which to draw a probability sample of CEE nationals in London. The study therefore relied on convenience sampling in order to generate a cost-effective sample that would be sufficiently robust for detailed analysis. This study adopted two sampling strategies (community and Internet) in order to ensure representation of key elements of the population and minimise bias. A detailed social mapping exercise was conducted prior to recruitment of the community sample. ${ }^{7}$ This provides some confidence that the selected boroughs and locations capture a broad cross-section of CEE migrants in London.

\section{Statistical analysis}

Standard statistical tests, for example, $\chi^{2}$ and Student's t, were used to examine associations between variables. Multivariate analysis of factors associated with one or more new heterosexual partner in previous 12 months used a backwards-stepwise model; all variables with a $\mathrm{p}$ value $<0.1$ for the crude association were retained for incorporation in the multivariate model. To evaluate reported behaviours with those of the British population we conducted a comparison with individual-level data from the National Survey of Sexual Attitudes and Lifestyles (Natsal) 2000 , the most recent national probability sample survey at the time of writing, conducted between May 1999 and February 2001. Logistic regression modelling was used to obtain adjusted ORs (aORs) to control for any variation in age, gender, marital status and education between the two data sources.

Due to the sample size, it was not possible to analyse by individual countries. Rather, because of the differing dates of accession (2004 vs 2007), we grouped respondents into two regions (the A8 and A2). Accession into Europe was dependent on countries fulfilling certain political and economic conditions, both have potentially influenced the sexual attitudes and behaviours of populations; in addition, there were tighter controls on A2 (compared with A8) migration to the UK. Also within the sociopolitical sciences, 'Eastern Europe' is often subdivided into Central Europe (the A8 states) and SouthEastern Europe (the A2). Historically, Central European political culture has been characterised as more rational, contractual and individualistic, while South-Eastern Europe is more essentialist, collectivistic and arbitrary. Over the centuries, this has resulted in different ways of thinking about individual freedoms, the boundaries between public and private and the role of the state-all of which influence attitudes and behaviours in society. ${ }^{8-10}$

The sample size of 2000 people provides $80 \%$ power to detect as significant the association with an explanatory factor where the difference in prevalence is around 6\%. A sample of this size also allows for adequately powered subgroup analysis. Analysis was performed using Intercooled STATA 8.0 (STATA Corp., College Station, Texas, USA) and SPSS 12.0 (SPSS Inc., Chicago, USA).

\section{RESULTS}

\section{Sample characteristics}

This CEE population sample $(\mathrm{n}=2648)$ was derived by merging the community sample $(n=2276)$ with the Internet sample $(n=372)$. The mean age of respondents was $29.0,51.4 \%$ were married or cohabiting, and almost half (48.3\%) of respondents were men (Supplementary table 1). The majority of respondents were Polish ( $n=1082,40.9 \%)$, Romanian ( $n=492,18.6 \%)$, or Lithuanian ( $\mathrm{n}=449,17.0 \%)$. The Internet sample was more likely to be born in an A8 country $(97.8 \%$ vs $74.2 \%, p<0.001)$, to be educated to degree level $(43.9 \%$ vs $29.4 \%, p<0.001)$ and in paid employment $(84.1 \%$ vs $72.8 \%, \mathrm{p}<0.001)$, than the community sample. Most respondents had migrated postaccession, 79.3\% arriving after May 2004. Those who arrived in the UK post-accession had been in the UK for a mean of around 1.5 years (median $17-9$ months). Three-quarters (74.6\%) of respondents had returned to their home country at least once in the past year and $15.0 \%$ had returned four or more times.

\section{Sexual behaviours}

Partners or sexual partners were defined as people who have had sex together-whether just once, or a few times, or as regular partners, or as married partners. This definition was made explicit in the questionnaire. Table 1 shows the distribution of reported numbers of partners (in the past year and past 5 years) by age and gender. There was substantial heterogeneity in numbers of heterosexual partners reported in the past 5 years; $70.3 \%$ of men and $48.8 \%$ of women reported more than one partner, whereas $29.1 \%$ of men and $6.9 \%$ of women reported more than five. Men consistently reported higher numbers of heterosexual partners than women over all time periods. Same-sex partnerships were reported by $3.4 \%$ of men and $4.0 \%$ of women.

Nearly half (44.9\%) of men and $29.1 \%$ of women had formed a new heterosexual partnership over the past year. The mean number of new partnerships in the past year varied from 5.3 among previously married men aged 25-34 to 0.1 among married women aged over 34 . The mean number of new partners declined with increasing age for men but not for women. Younger respondents were less likely to be in a married or cohabiting relationship. Across all age groups and both genders, new partner acquisition was highest among the single or previously married. Over half (55.6\%) of all male respondents were single or previously married; these men formed $74.0 \%$ of all new heterosexual partnerships by men in the past year.

Among those respondents reporting sex in the past year, a quarter of men and $7.6 \%$ of women reported relationships that were concurrent (overlapped or were simultaneous). Just over half $(51.5 \%)$ of men and most $(80.2 \%)$ women reported only one partner. The majority of new heterosexual partnerships in the past year were consummated in the UK. Approximately threequarters of most recent sexual partnerships were with nationals from the home country of the respondent $(75.6 \%$ for men and $71.1 \%$ for women). A UK national was the most recent sexual partner for $10.4 \%$ of men and $14.5 \%$ of women.

\section{STIs and HIV}

An ever previously diagnosed STI (excluding HIV) was reported by $11.1 \%$ of respondents. Most infections had not been diagnosed in the UK (table 2). A third of respondents had ever had an HIV test, and a third of these had their last HIV test in the UK. Just over $1 \%$ of respondents reported that they were HIV positive (18 men and 11 women), with $31.0 \%$ being diagnosed in the UK. The majority of respondents who reported being HIV positive were Polish ( $n=23,79 \%$ ). Risk factors for HIV in those respondents who reported being HIV positive were: previous injecting drug use $(n=2)$, sex between men $(n=1)$, six $(21 \%)$ had ever paid for sex but none reported having been paid for sex, and eight $(28 \%)$ reported a previous STI diagnosis. 
Table 1 Distribution of numbers of partners over past 5 years and past year by gender and age group

\begin{tabular}{|c|c|c|c|c|c|c|c|c|}
\hline & \multicolumn{4}{|c|}{ Men (age group (years)) } & \multicolumn{4}{|c|}{ Women (age-group (years)) } \\
\hline & $18-24$ & $25-34$ & $35+$ & All & $18-24$ & $25-34$ & $35+$ & All \\
\hline \multicolumn{9}{|l|}{ Past 5 years } \\
\hline Heterosexual partnerships & $\mathrm{n}=374$ & $\mathrm{n}=589$ & $n=250$ & $n=1213$ & $\mathrm{n}=470$ & $n=637$ & $\mathrm{n}=207$ & $n=1314$ \\
\hline 0 partners & $12.8 \%$ & $7.5 \%$ & $5.2 \%$ & $8.7 \%$ & $11.1 \%$ & $3.9 \%$ & $4.3 \%$ & $6.5 \%$ \\
\hline 1 partner & $16.3 \%$ & $19.2 \%$ & $32.8 \%$ & $21.1 \%$ & $35.7 \%$ & $46.0 \%$ & $60.9 \%$ & $44.7 \%$ \\
\hline 2 partners & $11.2 \%$ & $13.4 \%$ & $16.4 \%$ & $13.4 \%$ & $28.3 \%$ & $22.1 \%$ & $19.3 \%$ & $23.9 \%$ \\
\hline $3-5$ partners & $24.3 \%$ & $29.5 \%$ & $28.8 \%$ & $27.8 \%$ & $17.7 \%$ & $19.5 \%$ & $14.0 \%$ & $18.0 \%$ \\
\hline $6-10$ partners & $18.7 \%$ & $15.8 \%$ & $10.0 \%$ & $15.5 \%$ & $4.7 \%$ & $5.7 \%$ & $0.5 \%$ & $4.5 \%$ \\
\hline 11 or more partners & $16.6 \%$ & $14.6 \%$ & $6.8 \%$ & $13.6 \%$ & $2.6 \%$ & $2.8 \%$ & $1.0 \%$ & $2.4 \%$ \\
\hline 2 or more partners in past 5 years & $70.8 \%$ & $73.3 \%$ & $62.0 \%$ & $70.3 \%$ & $53.3 \%$ & $50.1 \%$ & $34.8 \%$ & $48.8 \%$ \\
\hline \multirow[t]{2}{*}{ Same sex partner in past 5 years } & $\mathrm{n}=378$ & $\mathrm{n}=606$ & $\mathrm{n}=271$ & $\mathrm{n}=1255$ & $\mathrm{n}=478$ & $\mathrm{n}=654$ & $\mathrm{n}=222$ & $\mathrm{n}=1354$ \\
\hline & $4.2 \%$ & $3.6 \%$ & $1.8 \%$ & $3.4 \%$ & $3.6 \%$ & $4.6 \%$ & $3.2 \%$ & $4.0 \%$ \\
\hline $\begin{array}{l}\text { Last heterosexual partner among those } \\
\text { who've ever had sex: }\end{array}$ & $\mathrm{n}=326$ & $\mathrm{n}=551$ & $\mathrm{n}=247$ & $\mathrm{n}=1124$ & $\mathrm{n}=420$ & $\mathrm{n}=616$ & $\mathrm{n}=208$ & $\mathrm{n}=1244$ \\
\hline From UK & $12.9 \%$ & $10.3 \%$ & $7.3 \%$ & $10.4 \%$ & $10.0 \%$ & $17.0 \%$ & $15.9 \%$ & $14.5 \%$ \\
\hline From home country & $69.6 \%$ & $76.4 \%$ & $81.8 \%$ & $75.6 \%$ & $78.1 \%$ & $66.6 \%$ & $70.2 \%$ & $71.1 \%$ \\
\hline From another country & $13.2 \%$ & $12.0 \%$ & $9.7 \%$ & $11.8 \%$ & $11.4 \%$ & $15.7 \%$ & $13.9 \%$ & $14.0 \%$ \\
\hline Don't know & $4.3 \%$ & $1.3 \%$ & $1.2 \%$ & $2.1 \%$ & $0.5 \%$ & $0.6 \%$ & $0.0 \%$ & $0.5 \%$ \\
\hline $\begin{array}{l}\text { Heterosexual partnerships in the past } \\
\text { year }\end{array}$ & $\mathrm{n}=353$ & $\mathrm{n}=559$ & $\mathrm{n}=235$ & $\mathrm{n}=1147$ & $\mathrm{n}=440$ & $\mathrm{n}=594$ & $\mathrm{n}=196$ & $\mathrm{n}=1230$ \\
\hline One or more new partners in past year & $46.7 \%$ & $46.9 \%$ & $37.4 \%$ & $44.9 \%$ & $35.0 \%$ & $27.6 \%$ & $20.4 \%$ & $29.1 \%$ \\
\hline $\begin{array}{l}\text { Among those who've had sex in the past } \\
\text { year: }\end{array}$ & $\mathrm{n}=284$ & $\mathrm{n}=504$ & $\mathrm{n}=201$ & $\mathrm{n}=989$ & $\mathrm{n}=391$ & $\mathrm{n}=569$ & $\mathrm{n}=169$ & $\mathrm{n}=1129$ \\
\hline Only one partner & $42.3 \%$ & $52.6 \%$ & $61.7 \%$ & $51.5 \%$ & $75.7 \%$ & $82.1 \%$ & $84.0 \%$ & $80.2 \%$ \\
\hline Serial monogamy & $29.6 \%$ & $23.2 \%$ & $14.9 \%$ & $23.4 \%$ & $15.1 \%$ & $10.2 \%$ & $12.4 \%$ & $12.2 \%$ \\
\hline Concurrency & $28.2 \%$ & $24.2 \%$ & $23.4 \%$ & $25.2 \%$ & $9.2 \%$ & $7.7 \%$ & $3.6 \%$ & $7.6 \%$ \\
\hline Mean number of UK consummated partners (SD) & $1.2(2.9)$ & $1.1(2.0)$ & $0.7(1.8)$ & $1.0(2.3)$ & $0.5(0.9)$ & $0.8(2.0)$ & $0.4(0.9)$ & $0.6(1.5)$ \\
\hline Mean number of partners without condom (SD)* & $1.2(2.0)$ & $1.1(1.7)$ & $1.0(1.6)$ & $1.1(1.8)$ & $1.9(18.9)$ & $0.8(1.0)$ & $0.7(0.6)$ & $1.1(11.1)$ \\
\hline \multicolumn{9}{|l|}{ New partners in past year } \\
\hline \multirow[t]{2}{*}{$1+$ new heterosexual partners } & $\mathrm{n}=353$ & $\mathrm{n}=559$ & $\mathrm{n}=235$ & $\mathrm{n}=1147$ & $\mathrm{n}=440$ & $\mathrm{n}=594$ & $\mathrm{n}=196$ & $\mathrm{n}=1230$ \\
\hline & $46.7 \%$ & $46.9 \%$ & $37.4 \%$ & $44.9 \%$ & $35.0 \%$ & $27.6 \%$ & $20.4 \%$ & $29.1 \%$ \\
\hline \multirow[t]{2}{*}{$1+$ new homosexual partners $†$} & $\mathrm{n}=377$ & $\mathrm{n}=606$ & $\mathrm{n}=271$ & $\mathrm{n}=1254$ & $\mathrm{n}=477$ & $\mathrm{n}=654$ & $\mathrm{n}=222$ & $\mathrm{n}=1354$ \\
\hline & $1.3 \%$ & $1.3 \%$ & $0.7 \%$ & $1.2 \%$ & $1.0 \%$ & $1.4 \%$ & $0.0 \%$ & $1.0 \%$ \\
\hline \multicolumn{9}{|c|}{ Number of new heterosexual partners in past year } \\
\hline Married: mean (SD) & $2.35(4.7)$ & $0.72(1.7)$ & $0.52(1.2)$ & $0.73(1.9)$ & $0.33(0.6)$ & $0.19(0.7)$ & $0.10(0.3)$ & $0.19(0.6)$ \\
\hline Cohabiting: mean (SD) & $1.19(2.6)$ & $0.90(1.9)$ & $0.63(1.8)$ & $0.96(2.1)$ & $0.34(0.6)$ & $0.52(2.1)$ & $0.6(1.9)$ & $0.46(1.6)$ \\
\hline Previously married: mean (SD) & $5.0(2.8)$ & $5.31(10.2)$ & $1.05(1.5)$ & $2.1(5.2)$ & $1.0(1.4)$ & $1.19(2.1)$ & $0.55(0.9)$ & $0.73(1.4)$ \\
\hline Single: mean (SD) & $2.18(7.5)$ & $1.69(2.9)$ & $1.95(3.6)$ & $1.93(5.5)$ & $0.66(1.1)$ & $0.94(2.6)$ & $0.24(0.6)$ & $0.75(1.8)$ \\
\hline All: mean (SD) & $2.00(6.6)$ & $1.40(3.1)$ & $0.88(1.9)$ & $1.48(4.4)$ & $0.50(0.9)$ & $0.52(1.9)$ & $0.32(0.9)$ & $0.48(1.4)$ \\
\hline
\end{tabular}

*Among those who have had sex in past year.

†Only includes men reporting anal intercourse with a homosexual partner.

Among the 546 (21\%) respondents who reported a recreational drug use in the past year, marijuana was most widely used $(87.8 \%)$, followed by ecstasy $(31.0 \%)$, cocaine $(23.4 \%)$, speed $(18.6 \%)$ and crystal-meth (5.4\%).

Table 2 Self-reported HIV and sexually transmitted infections (STIs)* and place of diagnosis

\begin{tabular}{lll}
\hline STI & $\begin{array}{l}\%(\mathbf{9 5 \%} \mathbf{C I}) \\
\mathbf{n = 2 2 9 6}\end{array}$ & $\begin{array}{l}\text { Proportion diagnosed } \\
\text { in the UK \% (95\% CI) }\end{array}$ \\
\hline Chlamydia & $2.7(2.1$ to 3.4$)$ & $44.4(31.9$ to 57.5$)$ \\
Genital herpes & $1.8(1.3$ to 2.4$)$ & $28.6(15.7$ to 44.6$)$ \\
Genital warts & $1.1(0.7$ to 1.6$)$ & $32.0(14.9$ to 53.5$)$ \\
Gonorrhoea & $2.0(1.4$ to 2.6$)$ & $15.6(6.5$ to 29.5$)$ \\
Non-specific urethritis & $0.5(0.2$ to 0.8$)$ & $18.2(2.3$ to 51.8$)$ \\
Pelvic inflammatory disease & $2.1(1.4$ to 3.1$)$ & $8.0(1.0$ to 26.0$)$ \\
(women only) & $0.6(0.3$ to 1.0$)$ & $15.4(1.9$ to 45.4$)$ \\
Syphilis & $1.2(0.8$ to 1.7$)$ & $21.4(8.3$ to 41.0$)$ \\
Trichomonas vaginalis & $1.1(0.8$ to 1.8$)$ & $31.0(15.3$ to 50.8$)$ \\
HIV & r. &
\end{tabular}

*Data based on self-reports of ever diagnosed infections rather than biological samples.

\section{Risk behaviours by region and sex}

Table 3 presents the prevalence of sexual behaviours, attitudes and drug use by sex and region of origin. Many risk behaviours varied by region and sex. Compared with their A2 counterparts, A8 respondents were more likely to report heterosexual oral or anal sex and recreational drug use in the past year. A8 men were more likely to have ever injected drugs $(6.6 \%$ vs $1.2 \%$, $\mathrm{p}<0.001$ ), while A8 women were more likely to report concurrent relationships in the past year, a same sex partner ever, and more heterosexual partners in the past year than those from the A2. Having paid for sex was widely reported across both regions but was more likely among men from the A2 countries ( $44.1 \%$ vs $28.5 \%, p<0.001$ ), as was concurrency in the past year $(32.2 \%$ vs $23.4 \%, p=0.019)$. A2 men were also more likely to have had an HIV test than A8 men (37.5\% vs $31.0 \%, p=0.032$ ), and to have used condoms consistently in the past 4 weeks, especially among those reporting two or more partners in the past year $(55.3 \%$ vs $34.8 \%$, p=0.002). A2 men and women were significantly less likely to be registered with a general practitioner (GP) although this association was lost when adjusted for time in the UK. 
Table 3 Prevalence of sexual behaviours and drug use: men and women by region of origin

\begin{tabular}{|c|c|c|c|c|c|c|}
\hline & \multicolumn{3}{|l|}{ Men } & \multicolumn{3}{|l|}{ Women } \\
\hline & $A 8 * n=939$ & $A 2+n=329$ & p Value $\ddagger$ & A8 $n=1097$ & A2 $n=264$ & p Value \\
\hline \multicolumn{7}{|l|}{ Heterosexual practices } \\
\hline Vaginal intercourse in past month & $61.2 \%$ & $53.4 \%$ & 0.057 & $70.1 \%$ & $76.0 \%$ & 0.374 \\
\hline Oral-genital contact in the past year & $69.0 \%$ & $60.6 \%$ & 0.008 & $61.6 \%$ & $44.6 \%$ & $<0.001$ \\
\hline Anal sex in the past year & $30.6 \%$ & $23.5 \%$ & 0.018 & $22.9 \%$ & $13.3 \%$ & 0.001 \\
\hline Condom used on all occasions, past 4 weeks ${ }^{* *}$ and: & $\mathrm{n}=224$ & $\mathrm{n}=76$ & & $\mathrm{n}=135$ & $\mathrm{n}=18$ & \\
\hline One partner past year & $31.6 \%$ & $29.6 \%$ & 0.913 & $24.9 \%$ & $30.1 \%$ & 0.197 \\
\hline Two or more partners past year & $34.8 \%$ & $55.3 \%$ & 0.002 & $34.1 \%$ & $33.3 \%$ & 0.950 \\
\hline All & $33.6 \%$ & $42.7 \%$ & 0.050 & $27.0 \%$ & $31.5 \%$ & 0.389 \\
\hline \multicolumn{7}{|l|}{ Risk perception } \\
\hline \multirow[t]{2}{*}{ More at risk of HIV in UK than home country } & $\mathrm{n}=767$ & $\mathrm{n}=271$ & & $\mathrm{n}=884$ & $\mathrm{n}=225$ & \\
\hline & $57.0 \%$ & $52.0 \%$ & 0.066 & $52.8 \%$ & $47.1 \%$ & 0.271 \\
\hline \multicolumn{7}{|l|}{ Sexual partnerships } \\
\hline Number of heterosexual partners past year: mean (SD) & $2.36(3.7)$ & $3.29(8.5)$ & 0.064 & $1.42(3.8)$ & $1.07(1.0)$ & 0.010 \\
\hline Ever had homosexual partners & $5.0 \%$ & $2.8 \%$ & 0.091 & $6.1 \%$ & $1.9 \%$ & 0.007 \\
\hline Concurrent partnerships, past year§ & $23.4 \%$ & $32.2 \%$ & 0.019 & $8.9 \%$ & $3.3 \%$ & 0.010 \\
\hline Ever paid for sex & $28.5 \%$ & $44.1 \%$ & $<0.001$ & NA & NA & NA \\
\hline Where paid for sex $(n=382)$ & & & 0.911 & & & NA \\
\hline UKब & $31.7 \%$ & $31.6 \%$ & & NA & NA & \\
\hline Home country $\Phi$ & $35.0 \%$ & $38.2 \%$ & & NA & NA & \\
\hline Both in UK and home country 9 & $17.1 \%$ & $15.4 \%$ & & NA & NA & \\
\hline Elsewhere & $16.3 \%$ & $14.7 \%$ & & NA & NA & \\
\hline \multicolumn{7}{|l|}{ Drug use } \\
\hline Ever injected non-prescribed drugs & $6.6 \%$ & $1.2 \%$ & $<0.001$ & $2.5 \%$ & $0.0 \%$ & NA \\
\hline Injected non-prescribed drugs in past year & $2.4 \%$ & $0.0 \%$ & NA & $1.3 \%$ & $0.0 \%$ & NA \\
\hline Recreational drug use in past year (excluding intravenous drugs) & $37.3 \%$ & $14.2 \%$ & $<0.001$ & $13.3 \%$ & $5.0 \%$ & $<0.001$ \\
\hline \multicolumn{7}{|l|}{ Sexual health } \\
\hline Ever had HIV test & $31.0 \%$ & $37.5 \%$ & 0.032 & $32.4 \%$ & $34.9 \%$ & 0.450 \\
\hline \multirow[t]{2}{*}{ Ever diagnosed with an STI (excludes candidiasis) } & $\mathrm{n}=798$ & $\mathrm{n}=277$ & & $\mathrm{n}=988$ & $\mathrm{n}=236$ & \\
\hline & $8.6 \%$ & $11.6 \%$ & 0.153 & $12.8 \%$ & $11.0 \%$ & 0.455 \\
\hline Registered with a general practitioner & $45.1 \%$ & $35.1 \%$ & 0.002 & $67.5 \%$ & $58.6 \%$ & 0.006 \\
\hline
\end{tabular}

*A8 refers to Czech Republic, Estonia, Hungary, Latvia, Lithuania, Poland, Slovakia and Slovenia.

†A2 refers to Bulgaria and Romania.

$\neq$ Comparing A8 with $\mathrm{A} 2$.

§Among those who had vaginal or anal sex in the past year.

ФMay also include men who have paid for sex elsewhere in addition to UK or home country.

**Restricted to those reporting sex in past 4 weeks, refers to anal or vaginal sex.

To examine high-risk sexual behaviour we calculated the $\mathrm{OR}$, $95 \% \mathrm{CI}$ and $\mathrm{aOR}$ of factors associated with one or more new heterosexual partners in the past year (Supplementary table 2). Male respondents reporting other risk behaviours in the same time period such as recreational drug use (aOR 1.37, 95\% CI 1.01 to 1.87 ), drinking alcohol on average three or more days a week (aOR 1.62, 95\% CI 1.14 to 2.28 ) and anal sex (aOR 1.89, 95\% CI 1.35 to 2.64 ) had increased odds of new heterosexual partners, as were those reporting a previous STI diagnosis (aOR 1.69, 95\% CI 0.99 to 2.86 ) or oral sex (aOR $3.6195 \%$ CI 1.64 to 3.31), while married or cohabiting men and men registered with a GP were less likely (aOR $0.35,95 \%$ CI 0.25 to 0.47 , and aOR $0.69,95 \%$ CI 0.51 to 0.93 respectively).

CEE women were more likely to have had new sexual partner(s) in the past year if they reported a same sex partner ever (aOR $2.31,95 \%$ CI 1.26 to 4.26 ), anal or oral sex in the past year (aOR $1.48,95 \%$ CI 1.01 to 2.15 and aOR $1.76,95 \%$ CI 1.23 to 2.52 respectively), drinking alcohol more frequently (aOR 1.68, 95\% CI 1.02 to 2.80 ) and a previous STI diagnosis (aOR 1.75, 95\% CI 1.13 to 2.73); they were less likely if they were married or cohabiting ( $\mathrm{aOR} 0.28$, 95\% CI 0.20 to 0.38 ), from the A8 compared with the A2 (aOR $0.60,95 \%$ CI 0.37 to 0.97 ), and over the age of 24 years (aOR $0.71,95 \%$ CI 0.51 to 0.98 ).

No association between time in the UK and most of the risk behaviours was found (data not shown). The notable exception was reporting of ever having had sex with someone of the same sex, which was more likely with increasing time in the UK $(p=0.034)$.

\section{Comparison with British national data}

Among respondents who reported heterosexual sex ever, the CEE sample was younger $(27.7$ vs 31.8 yrs, $p<0.001)$ than the Natsal sample, more likely to be single $(40.2 \%$ vs $35.0 \%$, $\mathrm{p}<0.001)$, and less likely to have a degree $(31.8 \%$ vs $35.8 \%$, $\mathrm{p}<0.001)$.

Significant behavioural differences between samples remained after adjusting for socio-demographic variables in multivariate analyses (table 4). Male CEE respondents were more likely to report two or more partners in the past year $(\mathrm{aOR} 2.1,95 \% \mathrm{CI}$ 1.3 to 2.1 ) and in the past 5 years (aOR $1.7,95 \%$ CI 1.6 to 2.6 ), but were less likely to report having had an STI (aOR 0.7; $95 \%$ CI 0.5 to 1.0 ) than Natsal respondents. CEE men were more than three times as likely to have paid for sex with a woman (aOR 3.2; 95\% CI 2.5 to 4.0) and twice as likely to have injected non-prescribed drugs (aOR 2.2; 95\% CI 1.3 to 3.9).

CEE women were three times more likely to have injected non-prescribed drugs than Natsal women (aOR 3.0, 95\% CI 1.1 to 8.1) and were less likely to report having had an STI (aOR 0.7, $95 \%$ CI 0.6 to 1.0). The proportion of female respondents reporting two or more partners in the past 5 years and in the 
Table 4 Multivariate analysis of risk behaviours comparing SALLEE respondents with Natsal* respondents

\begin{tabular}{|c|c|c|c|c|c|}
\hline Behaviour & $\begin{array}{l}\text { SALLEE } \dagger \\
(\mathrm{n}=\mathbf{2 3 2 3}) \%\end{array}$ & $\begin{array}{l}\text { Natsal } \dagger \\
(\mathrm{n}=2883, \\
1526) \neq \%\end{array}$ & $\begin{array}{r}\text { Crude OR } \\
(95 \% \text { CI) }\end{array}$ & $\begin{array}{l}\text { Adjusted OR } \\
(95 \% \mathrm{Cl}) \S\end{array}$ & p value \\
\hline Men & $\mathrm{n}=1102$ & $\mathrm{n}=1216,773 \ddagger$ & & & \\
\hline $2+$ partners (past year) & 45.0 & 29.4 & $2.0(1.6$ to 2.4$)$ & $1.7(1.3$ to 2.1$)$ & $<0.001$ \\
\hline Ever paid for sex with a woman & 35.5 & 15.8 & $2.9(2.3$ to 3.7$)$ & $3.2(2.5$ to 4.0$)$ & $<0.001$ \\
\hline Ever injected drugs & 5.9 & 2.4 & $2.6(1.5$ to 4.5$)$ & $2.2(1.3$ to 3.9$)$ & 0.005 \\
\hline Women & $n=1221$ & $\mathrm{n}=1667,753 \ddagger$ & & & \\
\hline $2+$ partners (past 5 years) & 52.9 & 40.9 & $1.6(1.3$ to 2.0$)$ & $1.2(1.0$ to 1.5$)$ & 0.058 \\
\hline $2+$ partners (past year) & 18.7 & 15.6 & $1.2(1.0$ to 1.6$)$ & $1.0(0.8$ to 1.3$)$ & 0.915 \\
\hline Ever injected drugs & 2.2 & 0.7 & $3.3(1.3$ to 8.8$)$ & $3.0(1.1$ to 8.1$)$ & 0.035 \\
\hline Consistent condom use (past 4 weeks) & 28.2 & 21.7 & $1.4(1.1$ to 1.8$)$ & $1.3(1.0$ to 1.8$)$ & 0.034 \\
\hline Ever diagnosed with STI & 12.8 & 18.1 & $0.7(0.5$ to 0.9$)$ & $0.7(0.6$ to 1.0$)$ & 0.038 \\
\hline
\end{tabular}

*National Survey of Sexual Attitudes and Lifestyles 2000.

†Restricted to London respondents aged 18-44 who reported ever having had sex (age range related to Natsal upper limit and SALLEE lower limit).

¥Unweighted, weighted denominator.

$\S$ Adjusted for age, relationship status, education: comparing SALLEE with Natsal respondents.

TCondoms used on all occasions of vaginal and/or anal sex in the past 4 weeks.

past year were similar across surveys. Consistent condom use in the past 4 weeks was higher in the CEE sample (aOR 1.3, 95\% CI 1.0 to 1.8$)$.

\section{DISCUSSION}

The accession of 10 CEE countries to the EU has resulted in one of the largest migratory influxes in peacetime British history. This project provides estimates of sexual behaviour patterns in these new communities. As would be expected we found wide variability in sexual lifestyles by gender, age, relationship status and region of origin. While reports of prior STIs are lower than in the general British population, CEE migrants, especially male migrants, report high rates of behaviours associated with increased risk of HIV and STI transmission. The benefits of more consistent condom use may be offset by higher rates of partner acquisition, paying for sex and injecting drug use.

Like other communities, heterosexual CEE migrants demonstrate assortative sexual mixing (whereby their most recent partner was from their home country). ${ }^{11} 12$ Nearly three-quarters of last sexual partnerships in the general CEE population sample were with a national from the home country of the CEE respondent. Risk of HIV and other STIs may increase as CEE communities become more integrated with the British population. Currently, the reported high-risk behaviours appear offset by low prevalence of infections within the CEE migrant community. With increasing time, it is possible that CEE migrants in the UK will have sexual partners from more diverse backgrounds, potentially increasing the likelihood of exposure to infections. ${ }^{5}$

STI screening opportunities differ in the UK compared with many CEE countries, ${ }^{13}$ which may impact on STI reports, especially on infections that are often asymptomatic. However, over $30 \%$ of respondents reported ever having an HIV test, higher than the $13 \%$ reporting an HIV test ever in the last Natsal survey. ${ }^{14}$

The reported HIV prevalence of $1.1 \%$ is substantially higher than the estimated prevalence of $0.09 \%$ in the general British population. ${ }^{15}$ This burden of infection is not, however, reflected in national HIV surveillance data. Although the numbers remain relatively small, there was a 10-fold increase between 2000 and 2007 in the total number (8-84), and proportion $(0.3 \%-2.3 \%)$, of all new HIV diagnoses in people from the A8. ${ }^{16}$ Eastern Europe does have the highest rate of HIV across Europe but Poland has one of the lowest. ${ }^{17}$ In Eastern Europe although the mode of acquisition is often unreported, ${ }^{18}$ the epidemic is believed to be largely driven by injecting drug use (a behaviour reported by $\sim 4 \%$ of our respondents), although heterosexual transmission is also on the increase. ${ }^{17} 18$

Only $31 \%$ of the reported HIV diagnoses were made in the UK. Potentially migrants may be aware of their HIV infection but not accessing services in the UK, and hence not impacting on national surveillance data as yet. This seems unlikely but is not impossible, especially as our qualitative data suggest people continue to access healthcare in home countries and use the Internet to obtain medications (Burns, unpublished data). In Central and Eastern Europe there is a high degree of stigma and discrimination attached to being HIV positive ${ }^{19-21}$; given that these data rely on self-reports a bias towards under-reporting of HIV seropositivity would be expected. Conversely, HIV-positive people may be more interested in sexual health matters which may impact on participation.

\section{Limitations}

The dilemma over how to interpret the HIV findings highlights one of the major limitations of our survey: the absence of biological samples. The high-risk behaviours reported suggest that blood-borne virus screening in this population would be informative and should be considered in future studies. A further limitation is that the data are based on self-reports. CEE populations are heterogeneous differing sociologically in ways that may impact on sexual attitudes and lifestyles, for example, religiosity and social liberalism. Numbers precluded analysis by specific country of origin, Polish, Lithuanian and Romanian respondents accounted for $76 \%$ of all data. A separate analysis was undertaken to ensure Polish responses did not substantially differ from responses from the other 'A8' nationalities combined; they did not (data not shown).

The limitations relating to convenience samples have previously been published. ${ }^{7}$ Natsal 2000 data were collected 9 years prior to these data. It is possible that the frequency of reported behaviours would have changed in the British population over this time. However, there is no more recent survey with which 
to compare our data until the Natsal 2010 data collection is completed. It is also possible that the sampling method may have created participation bias. Internet surveys of men who have sex with men show higher risk behaviours than the general population; ${ }^{22}$ however, these surveys use social networking sites used often to find sexual partners. None of the websites used to recruit for this study were social networking sites.

\section{Public health implications}

The economic recession has seen the rate of influx decline; however, large numbers of CEE nationals continue to migrate into the UK ${ }^{1}$ and many migrants have now made the UK their permanent home. The UK has a duty of care to ensure that appropriate risk reduction strategies are in place and these new communities are aware of and able to access these services. Paying for sex was reported by over a third of all CEE men. Further research is needed on the cultural factors associated with commercial sex, what type of sex is occurring and where, and the risks involved.

No association between time in the UK and many of the risk behaviours was found. The notable exception was participants reporting of ever having had sex with someone of the same sex, which was more likely with increasing time in the UK $(p=0.034)$. High-risk behaviours, regardless of time in the UK, support the concept of the migrant as a 'risk taker'. In Africa migration has been identified as a critical factor in high-risk sexual behaviour independent of marital and cohabitation status, social milieu or awareness of $\mathrm{HIV}^{23-25}$; it may be that this also holds true in other populations. Voluntary migrants are individuals who take a risk to travel to, and work in, environments that they hope will be beneficial to them. This risk-taking tendency may permeate into the choices they make in other areas of their lives. ${ }^{26}$

Migrants are often viewed as a health threat, yet evidence shows that the process of migration can present a health threat to migrants themselves. The 'healthy migrant' effect (whereby because of the health and human capital required for migration, immigrants are on average healthier than the population they originate from and often, also the population in their host country ${ }^{27}$ ) is likely to be evident in these new communities. Research, however, suggests that migrant health deteriorates more rapidly than the general population health with time. ${ }^{28}$ The mobile nature of migrant communities, language barriers and confusion over entitlement to services often means members are unlikely to benefit fully from public health programmes or access to health services. Men in particular were less likely to be registered with a GP yet reported significant risk behaviours for blood-borne viruses. While this study focused on sexual and reproductive health, there are, of course, many other aspects to health likely to be relevant to CEE migrants, and subsequently for their host nations. These include high rates of smoking, alcohol consumption and cardiovascular disease. ${ }^{29-31}$

A feature of CEE migration to the UK is that many people migrate for relatively short but recurring periods. ${ }^{1}$ Similarly, our respondents returned home frequently. In a borderless EU, management of chronic health conditions and surveillance of communicable diseases will increasingly involve transnational collaborations. Systems to monitor and facilitate transnational healthcare and disease surveillance for migrant communities are needed. Improving health outcomes for migrants are likely to benefit both the receiving (host) and home countries. ${ }^{32}$ This study helps illuminate our understanding of the sexual lifestyles, sexual and reproductive health risks, and health service needs of these migrant communities. Results from this study will help

\section{Key messages}

The accession of 10 CEE countries to the EU has resulted in the largest migratory influx in peacetime British history.

- This is the first study to provide estimates of sexual behaviour patterns in these new communities.

- High rates of partner acquisition, paying for sex and injecting drug use were reported; behaviours associated with increased risk of HIV and STI transmission.

- Reports of prior STIs were lower in CEE migrants to London than in the general British population, however, $1.1 \%$ reported being HIV positive.

- Heterosexual CEE migrants demonstrate assortative sexual mixing.

inform service planning and identify where STI and HIV interventions should be targeted. It also provides baseline data to help evaluate the effectiveness of interventions and provides a useful adjunct to interpreting data derived from other community- and clinic-based surveys.

Acknowledgements We are grateful for the expert guidance provided by our expert and community advisory boards, for the hard work and commitment of the fieldworkers who collected the data. We thank the staff and management at the Mortimer Market Centre, the Archway Sexual Health Clinic and the Margaret Pyke Centre; the websites that fielded the questionnaire; the many commercial, social and educational premises that facilitated recruitment for our fieldworkers; and everyone who took part in the study. This study was supported by the MRC Sexual Health and HIV Research Strategy Committee; the views expressed are those of the authors and not necessarily those of the MRC or the Health Departments.

Funding This research was supported by the MRC Sexual Health and HIV Research Strategy Committee (Grant: G0601703). The sponsor had no role in study design; the collection, analysis or interpretation of the data; the writing of the report; or the decision to submit the paper for publication.

\section{Competing interests None.}

Patient consent Obtained.

Ethics approval This study was conducted with the approval of the Camden \& Islington Community Research Ethics Committee, UK (07/H0722/110).

Contributors FB, CM, CG, RM, RF, JI, GH participated in the design of this study. AE VP and FB were responsible for study coordination and data collection. $F B, A E$ and $C M$ conducted the statistical analysis. FB was the lead writer of this paper. All authors have seen and approved the final version of this manuscript.

Provenance and peer review Not commissioned; externally peer reviewed.

\section{REFERENCES}

1. Home Office. Department for Communities and Local Government, Department for Work and Pensions, HM Revenue \& Customs. Accession Monitoring Report May 2004-March 2009. Crown Copyright, 2009.

2. Uuskula A, Puur A, Toompere K, et al. Trends in the epidemiology of bacterial sexually transmitted infections in eastern Europe, 1995-2005. Sex Transm Infect 2010:86:6-14

3. Hamers FF, Downs AM. HIV in Central and Eastern Europe. Lancet 2003:361:1035-44.

4. UNAIDS. Global Report: UNAIDS Report on the Global AIDS Epidemic 2010. Geneva: Joint United Nations Programme on HIV/AIDS (UNAIDS), 2010.

5. Evans AR, Hart GJ, Mole R, et al. Central and East European migrant men who have sex with men: an exploration of sexual risk in the UK. Sex Transm Infect 2011;87:325-30.

6. Evans AR, Mercer $\mathrm{CH}$, Parutis $\mathrm{V}$, et al. Factors associated with genitourinary medicine clinic attendance and sexually transmitted infection diagnosis among central and east European migrants in London. Sex Transm Infect 2011;87:331-6.

7. Evans AR, Parutis V, Hart G, et al. The sexual attitudes and lifestyles of London's Eastern Europeans (SALLEE project): design and methods. BMC Public Health 2009:9:399.

8. Berend I. The historical evolution of Eastern Europe as a region. Int Organ 1986; $40: 329-46$ 
9. Stokes G. Eastern Europe's defining fault lines. In: Ramet S, ed. Eastern Europe: Politics, Culture and Society Since 1939. Bloomington, IN: Indiana University Press, 2010:15-34.

10. Szucs J. Three historical regions of Europe. In: Keane J, ed. Civil society and the state. London: Verso, 1998.

11. Barlow D, Daker-White G, Band B. Assortative sexual mixing in a heterosexual clinic population-a limiting factor in HIV spread? AIDS 1997;11:1039-44.

12. Ford K, Sohn W, Lepkowski J. American adolescents: sexual mixing patterns, bridge partners, and concurrency. Sex Transm Dis 2002;29:13-19.

13. Riedner G, Dehne KL, Gromyko A. Recent declines in reported syphilis rates in eastern Europe and central Asia: are the epidemics over? Sex Transm Infect 2000;76:363-5

14. McGarrigle CA, Mercer $C$, Fenton $K A$, et al. Investigating the relationship between HIV testing and risk behaviour in Britain: analysis of the National Survey of Sexual Attitudes and Lifestyles 2000. AIDS 2005;19:77-84.

15. Health Protection Agency. Sexually Transmitted Infections in Black African and Black Caribbean Communities in the UK: 2008 Report. London: Health Protection Agency Centre for Infections, 2008

16. Delpech VC, Yin Z, Abernethy J, et al. The impact in the UK of the Central and Eastern European HIV epidemics. Epidemiol Infect 2009;137:1266-71.

17. EuroHIV. HIVIAIDS Surveillance in Europe. Mid-Year Report 2007. Saint Maurice: Institut de Veille Sanitaire, 2007. Report No: 76.

18. European Centre for Disease Prevention and Contro//WHO Regional Office for Europe. HIVIAIDS Surveillance in Europe 2008. Stockholm: European Centre for Disease Control \& Prevention, 2009.

19. Downes P. Living with Heroin: Identity, Social Exclusion and HIV among the RussianSpeaking Minorities in Estonia and Latvia. Tallinn: Legal Information Centre for Human Rights, 2003

20. Bozicevic I, Voncina L, Zigrovic L, et al. HIV epidemics among men who have sex with men in Central and Eastern Europe. Sex Transm Infect 2009;85:336-42.
21. Sarang A, Stuikyte R, Bykov R. Implementation of harm reduction in Central and Eastern Europe and Central Asia. Int J Drug Policy 2007;18:129-35.

22. Evans AR, Wiggins RD, Mercer CM, et al. Men who have sex with men in Great Britain: comparison of a self-selected internet sample with a national probability sample. Sex Transm Infect 2007;83:200-5.

23. Brockerhoff $\mathbf{M}$, Biddlecom AE. Migration, sexual behaviour and the risk of HIV in Kenya. Int Migrat Rev 1999;4:833-56.

24. Lurie MN, Williams BG, Zuma K, et al. The impact of migration on HIV-1 transmission in South Africa: a study of migrant and non-migrant men and their partners. Sex Transm Dis 2003;30:149-56.

25. Zuma K, Gouws E, Williams B, et al. Risk factors for HIV infection among women in Carletonville, South Africa: migration, demography and sexually transmitted diseases. Int J STD AIDS 2003;14:814-17.

26. UNAIDS. International Organisation for Migration, Duckett M. Migrants' Right to Health. Geneva, UNAIDS: UNAIDS Best Practice Collection, 2001. Ref Type: Serial (Book, Monograph).

27. Marmot MG, Adelstein AM, Bulusu L. Lessons from the study of immigrant mortality. Lancet 1984;1:1455-7.

28. Ronellenfitsch U, Razum 0. Deteriorating health satisfaction among immigrants from Eastern Europe to Germany. Int J Equity Health 2004:3:4.

29. Yusuf S, Reddy S, Ônpuu S, et al. Global burden of cardiovascular diseases. Circulation 2001;104:2746-53.

30. Kern J, Strnad M, Coric T, et al. Cardiovascular risk factors in Croatia: struggling to provide the evidence for developing policy recommendations. BMJ 2005; 331:208-10.

31. McKee M, Shkolnikov V. Understanding the toll of premature death among men in eastern Europe. BMJ 2001;323:1051-5

32. European Centre for Disease Prevention and Control/WHO Regional Office for Europe. Migrant Health: Background Note to the 'ECDC Report on Migration and Infectious Diseases in the EU'. Stockholm: European Centre for Disease Prevention and Control, 2009

\section{BOOK REVIEW}

\section{Gender, Sexuality, and Syphilis in Early Modern Venice: The Disease that Came to Stay}

Laura J McGough. Published by Palgrave Macmillan Basingstoke, 2010, pp 202. figs. 3. tables 4. charts 2 . ISBN 978-0-333-711941-1 (hardback), 978-0-333-80320-2 (paperback).

Accounts of aspects of Italian history written in English must be among some of the most frequently published from all the European countries. After all, given the circumstances, which scholar would not wish to study for some time in a land of ancient beautiful cities? Thus, I started to review this book with a fair amount of hardbitten cynicism, but I was more than pleasantly surprised to find it was extremely well researched and it has added much to my corpus of knowledge.

The author has done her research for this work thoroughly and taken expert advice not only from literary scholars and art historians but also from a whole group of internationally distinguished American scientists, physicians and epidemiologists in the field of sexually transmitted infections. Thus, from a medical reader's point of view the science is accurate. She weaves for the reader an understanding of the relationship of the major venereal disease of those times into the complex ongoing societal development of Venice over the best part of three centuries.
In the introduction, Laura McGough sets the pattern by an excellent explanation of the ever-changing fashions of medicine, its concept over many years of syphilis, the complex society of Venice, its authority to harbour wealth and the place of women in that society. These varied patterns are then minutely analysed and more fully described in subsequent chapters.

After the Introduction at the start of the first chapter, there is a quote on the lineage of syphilis from Voltaire's Candide. I would suggest every STD doctor should know that piece. Then the local circumstances that allowed for the spread of the 'French disease' are described. Venice was a wealthy city, which attracted and could only survive with a young workforce drawn from artisans from not only Northern Italy but also regions to the north and east of it. Most were unmarried. There was a shortage of even beds; sexual relationships were ever changing and often casual. The aristocracy of the city had rights that no one else had, a perfect breeding ground for an epidemic. Then there is a discussion on the 'beautiful prostitute' that linked women to masculine vulnerability. This is a theme exemplified in contemporary art and literature 'Noli me tangere'. The term meretrici, meaning women of suspect morals, not just prostitutes, was used over and over again, certainly a one-sided term as though men were the wounded party. There are good descriptions of what Italian physicians of those times conjectured and described about syphilis, the facilities offered not only treatment but also forms of aftercare, Incurabili, Zitelle, Convertite and Penitenti. The figures and occupations of those suffering from the French disease show how important is the keeping of archives, which do not destruct.

Lastly, there is a chapter on how historical examples of what went on in the past may be of some use in comparing the HIV/AIDS epidemic today.

The only minor criticism I have is the overuse of 'early modern' which seems to be used to describe anything past.

There are in such a work of scholarship excellent and full notes and a long bibliography. The author has written a beautiful and helpful book, which will help all interested in knowing more about how a history of our subject based on what happened in a rich and powerful city state, has much that is still apposite in present times.

Michael Anthony Waugh

Correspondence to Dr Michael Anthony Waugh 151 Roker Lane, Leeds LS28 9ND, UK mike@mawpud.fsnet.co.uk

Provenance and peer review Commissioned; not externally peer reviewed.

Published Online First 25 March 2011

Sex Transm Infect 2011;87:324.

doi:10.1136/sti.2011.049627 